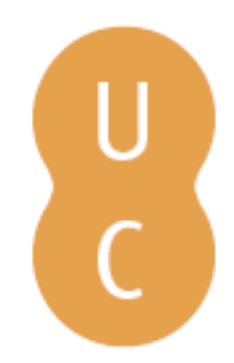

\title{
nommalina
}

\section{Uma nova estratégia pendular?: a política externa brasileira entre OCDE e BRICS}

Autor(es): $\quad$ Guimarães, Feliciano de Sá

Publicado por: Imprensa da Universidade de Coimbra

URL

persistente: URI:http://hdl.handle.net/10316.2/43160

DOI: $\quad$ DOl:https://doi.org/10.14195/978-989-26-1433-5_5

Accessed : $\quad$ 26-Apr-2023 10:47:26

A navegação consulta e descarregamento dos títulos inseridos nas Bibliotecas Digitais UC Digitalis, UC Pombalina e UC Impactum, pressupõem a aceitação plena e sem reservas dos Termos e Condições de Uso destas Bibliotecas Digitais, disponíveis em https://digitalis.uc.pt/pt-pt/termos.

Conforme exposto nos referidos Termos e Condições de Uso, o descarregamento de títulos de acesso restrito requer uma licença válida de autorização devendo o utilizador aceder ao(s) documento(s) a partir de um endereço de IP da instituição detentora da supramencionada licença.

Ao utilizador é apenas permitido o descarregamento para uso pessoal, pelo que o emprego do(s) título(s) descarregado(s) para outro fim, designadamente comercial, carece de autorização do respetivo autor ou editor da obra.

Na medida em que todas as obras da UC Digitalis se encontram protegidas pelo Código do Direito de Autor e Direitos Conexos e demais legislação aplicável, toda a cópia, parcial ou total, deste documento, nos casos em que é legalmente admitida, deverá conter ou fazer-se acompanhar por este aviso.

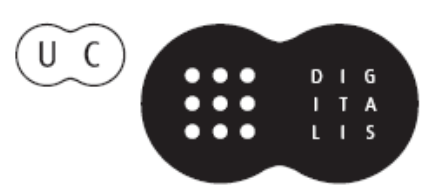




\section{Euro-Atlântico:}

\section{Espaço de Diálogos}

Isabel Maria Freitas Valente

Iranilson Buriti de Oliveira

(Coord)

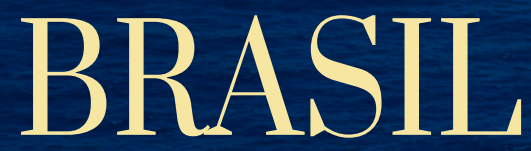

NAS ONDAS

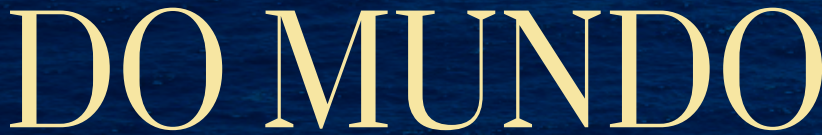

Álvaro Vasconcelos (Org)

Editora da Universidade Federal de Campina Grande

Imprensa da Universidade de Coimbra

2017 


\section{UMA NOVA ESTRATÉgIA PENDULAR? \\ A POLÍtica EXTERNA BRASILEIRA ENTRE OCDE E BRICS}

Feliciano de Sá Guimarães, $P h D$

IRI-USP

E-mail: felicianosa@usp.br

\section{Resumo}

Neste artigo argumentamos que o Brasil pode voltar a realizar uma estratégia pendular de política externa em moldes similares às décadas de 30 e 40. Isso é possível porque a atual configuração de poder global é marcada pela ascensão de alianças rivais - OCDE e BRICS - e o Brasil é um dos poucos países que podem exercer um papel pivotal. Os países centrais dessas alianças - China e EUA - disputam espaços de poder e influência, sendo as alianças um espaço importante de disputa. Isso permite aos governos brasileiros exercerem ações simultâneas de bandwagoning e soft-balancing, algo impensável em ordens globais anteriores. Além disso, a proliferação de complexos de regimes dá ao Brasil uma rede de proteção institucional contra eventuais punições por comportamentos pendulares.

Palavras-chave: BRICS; OCDE; soft-balancing; bandwagoning; forum-shopping 


\begin{abstract}
In this article, we argue that Brazil can return to a pendulary foreign policy strategy similar to the 1930s and 1940s. This is possible because the current configuration of global power is marked by the rise of rival alliances - OECD and BRICS - and the Brazil is one of the few countries that can play a pivotal role in this scenario. The central countries of these alliances - China and the US - compete for power and influence, and alliances are an important area of contention. This allows Brazilian governments to take simultaneous actions of bandwagoning and soft-balancing, something unthinkable in previous global orders. In addition, the proliferation of complex regimes gives Brazil a network of institutional protection against eventual punishments for commuting behavior.
\end{abstract}

Keywords: BRICS; OCDE; soft-balancing; bandwagoning; forum-shopping

\title{
Introdução
}

Em um clássico da interpretação da política externa brasileira do Entre Guerras, Stanley Hilton cunhou o conceito de "diplomacia pendular" para a política externa brasileira. Para o autor, o Brasil "jogava as grandes potências - EUA e Alemanha - uma contra a outra, utilizando pressão ou suposta pressão como uma alavanca para levantar concessões" ${ }^{66}$. Posteriormente, Gerson Moura, em outro texto clássico para o período, cunhou o conceito de "equidistância pragmática" para caracterizar o posicionamento brasileiro perante EUA e Alemanha. Para o autor, "durante o processo de abertura relativa dos anos 30, o Brasil fez o jogo da equidistância ou equilíbrio pragmático face às grandes potências (...) Em contrapartida, estes países logo se conscientizaram da importância do

66 HILTON - Brazil and the Great Powers, 1930-1939 - The Politics of Trade Rivalry, p. 225 . 
Brasil para o esforço de guerra (...), uma circunstância que magnificou de forma clara a capacidade de negociação do Brasil em suas relações internacionais" 67.

A atual configuração de poder global permite uma reedição atualizada desse pêndulo? Com efeito, a ordem global contemporânea não lembra em muitos aspectos, notadamente em seus aspectos estruturais, a situação ocorrida no Entre Guerras e Segunda Guerra. Contudo, neste ensaio sustentamos que, no que diz respeito ao posicionamento do Brasil, a atual configuração de poder global permite ao país exercer uma diplomacia pendular em moldes similares aquilo que havia nos anos 30 . $\mathrm{O}$ antagonismo crescente entre China e EUA, mais notadamente entre OCDE e BRICS, permite ao Brasil a exercitar movimentos pendulares na busca de ganhos políticos e econômicos concretos. Isso é possível por conta de três razões. Primeiro, o Brasil é hoje o único país membro de ambas as alianças. Segundo, a transição de poder global contemporânea, ao contrário dos anos 30, é caracterizada por mudanças suaves de poder que se consolidam em alianças rivais. Essas alianças rivais disputam espaço de poder e novos membros na ordem global. Ao se posicionar no meio o Brasil é disputado por ambas alianças. Por fim, a proliferação de instituições internacionais - caracterizada pelos complexos de regimes - fornece uma rede de proteção contra eventuais punições ao Brasil pelas grandes potências por conta de eventuais movimentos pendulares.

Este artigo é dividido em quatro partes. Primeiro, discorremos sobre a atual transição de poder global e a formação de alianças. Segundo, caracterizamos as alianças OCDE e BRICS dentro do contexto de transição. Terceiro, discutimos a proliferação de instituições internacionais e como isso abre espaço para uma ação pendular do Brasil. Por fim, demonstramos mais precisamente como e porque o Brasil pode agir

67 MOURA - Relações Exteriores do Brasil 1939-1950: mudanças na natureza das relações Brasil-Estados Unidos durante e após a Segunda Guerra Mundial, p. 255. 
como pêndulo em um contexto de duas alianças suavemente rivais e a proliferação de instituições internacionais.

\section{A transição de poder global e a formação das alianças}

É possível pensar alianças econômicas como OCDE e BRICS usando teorias sobre alianças estratégicas e de segurança? Acreditamos que sim. $\mathrm{Na}$ verdade, uma parte importante dos estudos sobre coalizões comerciais $^{68}$ é construída a partir de teorias estratégicas. Nesse contexto, as alianças OCDE e BRICS poderiam ser consideradas rivais nos mesmos moldes das alianças de segurança? Ou ainda, os polos de poder - EUA e China - enxergam OCDE e BRICS como campos antagônicos de disputa política?

Dentro de uma chave explicativa puramente estratégica, a resposta a essas perguntas começa pela discussão sobre transição de polaridades. Há pelo menos quatro visões predominantes na literatura sobre a atual configuração global de poder. Primeiro, os defensores da unipolaridade sustentam que atual configuração de poder global é definida pela existência de um único polo de poder global ainda insuperável em termos militares. Há divergências sobre o teor dessa unipolaridade em termos de valores ${ }^{69}$ ou agressividade ${ }^{70}$, mas todos comungam da ideia de que no pós-Guerra Fria não há nenhum poder capaz de superar os EUA. Segundo, há aqueles que defendem a tendência bipolar do sistema internacional. Isto é, a lógica do dilema da segurança levaria a uma lenta e gradual exclusão de múltiplos polos de poder ou a ascensão de um polo rival até que duas grandes potências se equilibrariam e estabele-

68 NARLIKAR - International Trade and Developing Countries Bargaining coalitions in the GATT \& WTO.

69 IKENBERRY - Liberal Leviathan: The Origins, Crisis, and Transformation of the American World Order.

70 WOHLFORTH - "U.S. Strategy in a Unipolar World". In America Unrivaled: The Future of the Balance of Power; WALT - "Alliances in a Unipolar World"; MEARSHEIMER - The Tragedy of Great Power Politics.; e MONTEIRO - Theory of Unipolar Politics.. 
ceriam uma paz armada ${ }^{71}$. Terceiro, a ordem global é tendencialmente multipolar e potências regionais em ascensão buscam reformar e/ou recriar a ordem global conforme seus interesses e valores ${ }^{72}$.

Nesse contexto, como se constroem as alianças? Segundo Walt, apesar dos arranjos das alianças variarem enormemente, o elemento essencial que cria uma aliança é um compromisso comum em torno de um apoio mútuo contra uma ameaça. Assim, para o autor as alianças são fruto de ameaças oriundas de potências que, ao almejarem supremacia, produzem pelo menos dois tipos de comportamentos racionais dos mais fracosbandwagoning e balancing. Isto é, ou os Estados se aliam à potência preponderante e ao fazê-lo esperam certa proteção contra rivais regionais e outras potências extra-regionais; ou buscam alianças contra-hegemônicas que procuram equilibrar a distribuição de poder concentrada nas mãos de um ator global decisivo. Quando confrontados com uma ameaça externa significativa, os Estados podem equilibrar ou seguir o líder. Assim, por um lado, o equilíbrio é definido pela aliança contra a ameaça predominante e, por outro, o bandwagoning se refere ao alinhamento com a fonte desse perigo ${ }^{73}$. Voltaremos a esses conceitos mais adiante.

Porém, alianças não são fruto exclusivo de decisões estratégicas calculadas em termos de poder material. As implicações da formação da identidade coletiva para a criação e manutenção das alianças também importam. Se os Estados pertencem a uma aliança por causa de sua identificação mútua e coletiva, problemas de ganhos relativos, coordenação, verificação, e sanções se tornam menos relevantes ${ }^{74}$. Vale ressaltar que

71 WALTZ - Theory of International Politics e "Structural Realism after the Cold War".

72 ACHARYA - The End of American World Order; STUENKEL - "Emerging powers and status: the case of the first BRICs summit".

73 WALT - "Alliances in a Unipolar World", p. 17.

${ }^{74}$ Ao fazer a distinção entre alianças e acordos de segurança coletiva, Wendt fornece uma ilustração instrutiva da diferença entre valores e considerações estratégicas. As alianças são meras coalizões temporárias de Estados interessados que se reúnem por razões instrumentais em resposta a uma ameaça específica. Uma vez que a ameaça se foi, a coalizão perde sua lógica e sofre uma debandada. Em contraste, nos sistemas de segurança 
em alianças baseadas em identidade coletiva certos Estados demonstram disposição para as perdas. Em outras palavras, as identidades coletivas não violam suposições da busca do interesse próprio, como querem os realistas. Em vez disso, envolvem uma redefinição dos indivíduos em termos coletivos 75 .

Contudo, em nossa visão as dificuldades de se alcançar a identidade coletiva tornam improvável que a força motivacional das identidades egoístas entre os Estados possa ser totalmente eliminada. A questão é que a formação e o sentido das alianças pode ser lida pelos tomadores de decisão tanto por meio das ações puramente racionais e estratégicas como por meio dos valores compartilhados e suas dificuldades de construção coletiva. O grande dilema é exatamente entender como mudanças nas polaridades abrem espaço para os momentos de inflexão que pressionam tanto a criação de novas alianças como o processo por meio do qual Estados membros e Estados criadores compartilham valores e permitem que novos membros adiram ao conjunto normativo da aliança. Nesse contexto, o espaço aberto pelas transições de polaridades, e o consequente rearranjo de alianças, coloca os países periféricos dentro do dilema de como se posicionar perante as alianças dominantes do sistema, tanto do ponto de vista estratégico como do ponto de vista dos valores.

Mais precisamente, quais seriam os mecanismos de transição de polaridades e seus efeitos sobre a formação das alianças? Segundo Chius ${ }^{76}$ a formação de alianças parece ser mais estimulada em momentos de mudanças de poder relativo dos Estados, exatamente quando o nível de desenvolvimento das grandes potências sofre um declínio acentuado

coletiva, os Estados assumem compromissos identitários contra ameaças não específicas ou sistêmicas (WENDT - "Identity Formation and the International State", p. 386).

75 Para Narlikar, op. cit. pp. 27-28, uma abordagem que leve identidades em consideração enfatiza a importância das ideias ao condicionar, mudar e cimentar interesses dos Estados; assim como enfatiza as identidades contruídas coletivamente pelos Estados e suas alianças. Em ambos os casos, a identificação de Estados like-minded uns com os outros são a base da formação das coalizões.

${ }^{76}$ CHIUS - "International Alliances in the Power Cycle Theory of State Behaviour". 
ou quando potências rivais passam por um forte aumento. Tais mudanças alteram as percepções de ameaça e, assim, as motivações para as alianças. Esses pontos críticos envolvem um número de fatores que são freqüentemente apontados como contribuintes para a formação e reconstrução de alianças: mudanças no poder relativo (e, portanto, no equilíbrio de poder), mudanças nas taxas de crescimento econômico e aumentos na percepção de ameaças ${ }^{77}$. Nesse sentido, na medida em que os momentos críticos de transição incluem simultaneamente todos esses fatores, a leitura dos tomadores de decisão sobre os caminhos e tendências das polaridades se torna embaçada, dificultando o cálculo dos riscos e aumentando os custos de oportunidade das escolhas.

Contudo, a abordagem de Chius enfatiza apenas fatores domésticos como mecanismos de transição. Como argumenta $\mathrm{Kim}^{78}$, os teóricos da transição de poder consideram o desenvolvimento interno como a principal fonte de mudanças no poder. Os meios externos para aumentar o poder nacional, incluindo a formação de alianças, não são considerados cruciais. Eles argumentam que mesmo que as alianças façam a diferença, elas não serão eficazes porque elas não podem ser feitas ou desfeitas facilmente. Para a autora, contudo, deve-se considerar não apenas as capacidades internas de cada grande poder, mas também levar em conta o apoio potencial de seus aliados. $\mathrm{O}$ uso de capacidades internas como único indicador para medir o poder de cada nação não é suficiente.

É exatamente assim que se encontra a atual configuração de poder global. Os três fatores transicionais apontados acima por Chius - mudanças no poder relativo entre as grandes potências, nas taxas de crescimento econômico e na percepção de ameaças - ocorrem simultaneamente e dificultam a leitura das tendências e dos riscos. Nesse contexto, as estratégias de equilíbrio de poder ou bandwagoing se tornam tanto

\footnotetext{
77 Ibidem, p. 133.

78 KIM - "Alliance Transitions and Great Power War", pp. 833-835.
} 
expressões estratégicas momentâneas dos Estados periféricos como fonte de potencial conflito entre os polos.

Isto é, conforme aponta Kim, os polos competem pelas estratégias momentâneas dos Estados periféricos dentro da necessidade de retardar a queda ou consolidar a ascensão de poder. Assim, ao contrário do pensamento de Walt para quem as alianças só poderiam colapsar se houvessem mudanças na percepção de ameaça e queda na credibilidade da aliança em prover o bem coletivo e identitário proposto ${ }^{79}$, neste ensaio preferimos ver as alianças como um campo de disputa entre os polos. Com o intuito de aumentar seu poder relativo, os polos procuram atrair novos membros e manter os atuais por meio da geração de ganhos coletivos e proteção. Uma mudança de posição de determinado membro de uma aliança para outra ou mesmo a defecção desse membro significa uma perda de poder relativo da grande potência.

Nesse sentido, se por um lado a discussão sobre a transição de poder entre as grandes potências diz respeito à durabilidade da polaridade vigente - e os valores que a sustenta -, por outro, as alianças são fontes de conflito que podem afetar essa durabilidade. Isto é, as alianças não são apenas resultado de estratégias frente à distribuição de poder ou da construção de normas e identidades coletivas, mas espaços de disputas de poder tanto material como ideacional que impactam na longevidade da configuração de poder vigente.

Há duas críticas importantes à transição de poder entre grandes potências no cenário contemporâneo. Uma vinda dos defensores da transição pacífica e outra vinda dos unipolaristas. Em uma visão benigna sobre a transição de poder, Kupchan ${ }^{80}$ busca incorporar aspectos materiais e ideacionais enumerando três condições que caracterizam o processo de transição pacífica de poder, uma transição onde as alianças têm um papel pouco relevante. Em primeiro lugar, o país hegemônico e

\footnotetext{
79 WALT - "Why alliances endure or collapse", pp. 158-160.

80 KUPCHAN - "Introduction: Explaining Peaceful Power Transition”, pp. 8-9.
} 
o país desafiante envolvem-se em um processo sustentado de restrição estratégica e acomodação mútua que, em última instância, lhes permite ver um ao outro como potências benignas. Segundo, a transição pacífica emerge da contestação ideacional entre o ator hegemônico e o desafiante quanto às normas e acordos sobre os contornos de uma nova ordem internacional. Finalmente, a transição pacífica não depende apenas da capacidade do hegemon e do desafiante em forjar acordos, mas também em suas respectivas capacidades de legitimá-los.

Já entre aqueles que não acreditam na transição de poder, dado que unipolaridade definiria o atual sistema internacional, as alianças devem ser repensadas dentro de um contexto no qual não há espaço para se opor aos EUA. Para Walt, as estruturas da aliança herdadas da Guerra Fria estão em mutação e é improvável que persistam na sua forma atual. No entanto, em vez de confiar em estruturas fixas, multilaterais e altamente institucionalizadas, os EUA dependerão mais fortemente de coalizões ad hoc e acordos bilaterais que maximizem seu interesse e liberdade de ação. Para o autor, esforços para restringir o poder dos EUA não assumirão o formato de coalizões claramente anti-hegemônicas, a não ser que os EUA adotem uma abordagem extremamente agressiva em relação a certas partes do mundo ${ }^{81}$.

Contudo, o que nos parece claro é que Walt se equivoca ao não considerar as mudanças que vêm ocorrendo com o aumento do poder relativo da China e, notadamente, o peso das alianças como um indicador de ascensão e queda dos polos. Nesse sentido, como argumenta T.V. Paul ${ }^{82}$, essas condições são bastante rigorosas e não correspondem claramente à atual dinâmica entre os Estados Unidos e a China. Além disso, não é incluída na análise a importância das alianças seja para acelerar ou retardar a transição pacífica.

81 WALT - "Alliances in a Unipolar World", p. 119.

82 PAUL - "Soft Balancing in the Age of U.S. Primacy", p. 09. 
De fato, as estruturas da Guerra Fria têm dificuldades em se manter, mas isso tem menos a ver com a supremacia americana e mais com a força de atração que um novo polo de poder tem sobre partes importantes do globo e que acelera os três fatores de transição colocados por Chius, além de permitir que as alianças sejam alvos de aumento de poder relativo, como observado por Kim.

\section{OCDE E BRICS}

Dentro do contexto de transição colocado acima no qual as alianças se tornam foco de competição, OCDE e BRICS são fruto de dois tipos de ação internacional dos países membros: bandwagoning e soft-balancing. Enquanto o primeiro define a ação dos Estados em relação à OCDE, o segundo caracteriza os BRICS. Como veremos, contudo, ambas estratégias são possíveis ao Brasil.

A OCDE pode ser caracterizada como a típica aliança bandwagoning. Walt definiu o conceito ao afirmar que "seguir o líder refere-se ao alinhamento com a fonte de perigo" 83 . No entanto, conforme afirmou Schweller, o conceito de Walt equaliza bandwagoning à capitulação e está muito ligado a ameaças iminentes ou significativas. Assim, o que ocorre quando não se observam situações em que as ameaças são tão iminentes? Schweller argumenta que "prevenir perdas relativas em poder e prestígio é um bom conselho para Estados satisfeitos que buscam, acima de tudo, manter aquilo que já possuem. Por outro lado, permanecer no mesmo lugar não é o objetivo principal dos Estados revisionistas. Eles querem aumentar, e não apenas preservar, seus valores fundamentais e melhorar sua posição no sistema. Esses objetivos não podem ser alcançados simplesmente assegurando que todos os outros não obtenham ganhos. Eles devem ganhar em relação aos outros" 84 .

83 WALT - The Origins of Alliances, p. 17.

${ }^{84}$ SCHWELLER - "Bandwagoning for Profit Bringing the Revisionist State Back In", p.87. 
$\mathrm{O}$ autor sugere pensar bandwagoning não apenas em termos de ameaças, mas também em termos de ganhos. Os Estados seguem o líder na busca de ganhos e não apenas proteção ${ }^{85}$. Esse parece ser o caso das estratégias de muitos países em relação à OCDE. Mais do que se proteger contra ameaças externas iminentes, a OCDE representa uma aliança de identidades compartilhadas em torno do liberalismo econômico e da democracia liberal cujo centro são os EUA e a Europa Ocidental. Esses países não são a fonte do perigo, mas sim base de ganhos econômicos e políticos para países que aderirem ao modelo. Tornar-se membro da OCDE significa aderir a certos valores e, em troca, se espera dos novos membros um comportamento internacional que favoreça os líderes e sua posição de status quo.

De acordo com Davis ${ }^{86}$, a seleção para novos membros da OCDE está altamente correlacionada com as decisões dos países em empreender reformas econômicas recomendadas pela OCDE, além de melhorar as relações com os atuais membros. Porém, a seleção de membros não é apenas uma função da trajetória da reforma econômica e das boas relações políticas com os membros fundadores. Não é por acaso que a Turquia foi um dos membros fundadores da OCDE porque era beneficiária da ajuda do Plano Marshall e membro da OTAN, enquanto que a adesão de países da Europa do Leste só veio com o fim da Guerra Fria. A democracia também se tornou um critério para a adesão. Assim, especula-se que democracia, boas relações políticas com o Ocidente e reformas econômicas liberais possam ser os indicativos mais próximos das razões para a adesão, embora não haja consenso sobre isso. Em resumo, as motivações para a adesão à OCDE incluem aquilo que esperamos: considerações materiais, estratégicas e ideacionais.

85 Idem.

86 DAVIS - More than Just a Rich Country Club: Membership Conditionality and Institutional Reform in the OECD, p.3. 
Os BRICS, por sua vez, podem ser caracterizado com a típica aliança balancing, porém não nos moldes de Walt, para o qual o equilíbrio significa se aliar ao lado mais fraco tendo em vista uma ameaça iminente vinda da potência dominante ${ }^{87}$. Os BRICS podem ser caracterizados como uma aliança de soft-balancing cujo principal objetivo é melhorar a posição de barganha de seus membros no cenário internacional ${ }^{88}$.

Para alguns, os BRICS representam uma forma de multilateralismo que "partilha de encargos" como "partilha de benefícios" como principais impulsionadores da sua criação ${ }^{89}$. Outros veem os BRICS como um subproduto das iniciativas de busca de status e que a dinâmica de clubes entre os membros ajudou a contornar os conflitos internos por conta do interesse de aumentar o status global $^{90}$.

Os BRICS compartilham identidades em torno de um certo tipo de capitalismo de Estado e reformismo global das instituições. Não se trata, portanto, de uma aliança hard-balancing baseada em duras medidas como aumento de armamento em escala global em resposta a ameaças existenciais que colocam em risco a soberania dos países membros, mas sim de um equilíbrio suave de identidades compartilhadas em torno de um modelo econômico e um reformismo propositivo e inovador, sendo o New Development Bank o mais recente exemplo91.

87 WALT - The Origins of Alliances, p. 17)

88 Abdenur et al - "BRICS and Global Governance: a two-pronged approach"; STUENKEL - "Emerging powers and status: the case of the first BRICs summit" e The BRICS and the Future of Global Order; SCHAEFER e POFFENBARGER - The Formation of the BRICS and Its Implication for the United States: Emerging Together; $e$ BOND -"BRICS and the sub-imperial location".

${ }^{89}$ HAMPSON e HEIMBECKER - "The 'new' multilateralism of the twenty-first century".

90 Cooper e Farooq, 2015

${ }^{91}$ Existem diferentes interpretações para as razões do equilíbrio suave ser a estratégia dominante na ordem pós-Guerra Fria. Para Wohlforth países como Rússia e China até se sentem incomodados com o unilateralismo dos EUA, mas adotam posturas de equilíbrio suave porque simplesmente não encontram países dispostos a fazer um equilíbrio agressivo por conta do caráter liberal da política externa americana (2004, pp. 214-220). Para Ikenberry, os potenciais rivais dos EUA têm evitado um equilíbrio agressivo por causa da possibilidade e capacidade de influenciar a política externa americana seja por meio das instituições domésticas em Washington, seja por meio das instituições internacionais 


\section{As instituições internacionais}

Em um ambiente no qual bandwagoning da OCDE e soft-balancing dos BRICS, ambas estratégias pensadas em termos de ganhos, os complexos de regimes entram em cena e se tornam uma importante rede protetora para um país como o Brasil. O que são complexos de regimes? Complexo de regimes significa a existência de instituições aninhadas (nested), paralelas e sobrepostas que não estão organizadas hierarquicamente dentro de uma área específica da ordem global. Para alguns, um complexo de regimes é uma rede de três ou mais regimes que se relacionam em uma área de assunto comum, exibindo sobreposição de funções e associações, gerando interações potencialmente problemáticas e instáveis ${ }^{92}$.

A literatura mostra que entre um regime com um único instrumento jurídico integrado e arranjos altamente fragmentados existem complexos de regime de vários graus de hierarquia, abrangência e funções sobrepostas $^{93}$. Embora a complexidade de regras sobrepostas também exista no âmbito doméstico, a falta de hierarquia no nível internacional distingue a complexidade do regime internacional, tornando mais difícil localizar com precisão onde a autoridade política sobre determinada questão reside ${ }^{94}$.

existentes (2011, pp. 126). T. V. Paul vai na mesma linha ao afirmar que as grandes potências de segunda ordem não se equilibraram agressivamente com os Estados Unidos porque "ao contrário das potências hegemônicas ou emergentes do passado, os EUA não parecem desafiar a existência soberana de outros estados, exceto alguns países regionais isolados (por exemplo, o Irã)" (2005, pp. 53).

92 ALTER e MEUNIER - "The Politics of International Regimes Complexity"; BUSCH - "Overlapping Institutions, Forum Shopping, and Dispute Settlement in International Trade"; HAFNER-BURTON - "The Power Politics of Regime Complexity: Human Rights Trade Conditionality in Europe"; ORSINI et al - "Regime Complexes: a buzz, a boom or a boost for Global Governance?".

93 KEOHANE e VICTOR - "The Regime Complex for Climate Change"; RAUSTIALA e VICTOR - "The Regime Complex for Plant Genetic Resources".

${ }^{4}$ ALTER e MEUNIER - op. cit.,p. 13. 
Em outras palavras, complexos de regimes são múltiplas instituições internacionais que operam e regulam a mesma área da ordem global. Não se pode dizer que o comércio internacional, por exemplo, é regulado exclusivamente pela Organização Mundial do Comércio. Na verdade, são centenas de acordos, tratados e organizações regionais que regulam o comércio e os Estados agem simultaneamente em todas elas. Com o aumento incessante das instituições internacionais nas últimas décadas - os autores Johnson e Urpelainen ${ }^{95}$ estimam quase $5.000 \mathrm{em}$ funcionamento - os complexos de regimes se tornaram dominantes em todas as áreas reguladas, sendo praticamente impossível uma ação de política externa que não seja afetada pelas restrições e proteções do direito internacional observado nos tratados vigentes.

Dentro desse contexto de proliferação institucional, qual seria a estratégia mais comum para os Estados atingirem seus objetivos? Ou seja, como há diversas instituições internacionais que regulam a mesma área temática, como um Estado agiria frente à sobreposição e o paralelismo institucional? A literatura mostra que os Estados escolhem fóruns institucionais de acordo com os interesses, o momento e as expectativas em torno de ganhos concretos. Eles fazem isso sem deixar de participar dos demais que porventura não representem naquele instante a melhor alternativa. Assim, esse forum shopping é uma estratégia que busca selecionar instituições que melhor promovam políticas específicas com o objetivo de obter uma decisão que favoreça os interesses dos Estados ${ }^{96}$.

Se os complexos de regimes abrem espaço para que oforum shopping seja uma estratégia dominante na regulação de temas internacionais, um país como o Brasil pode transformar tal estratégia em um instrumento importante para seu posicionamento global perante BRICS e OCDE. Como veremos na próxima seção, sustentamos que o forum shopping

95 JOHNSON e URPELAINEN - "International Bureaucrats and the Formation of Intergovernmental Organizations: Institutional Design Discretion Sweetens the Pot.

96 ALTER e MEUNIER - op.cit., p. 16. 
pode adquirir simultaneamente um caráter de bandwagoning e soft-balancing para o Brasil.

\section{Brasil e a estratégia pendular}

Conforme o cenário apontado acima, três fatores compõem um cenário no qual o Brasil pode agir de forma pendular. Primeiro, um sistema internacional cuja transição de poder é permeada pela construção de alianças razoavelmente rivais. Segundo, essas alianças competem por mais membros ou procuram assegurar os atuais por meio da geração de ganhos coletivos. Terceiro, uma governança global marcada pela fragmentação institucional, sobreposição de funções institucionais e expansão de complexos de regimes que fornece uma rede de proteção contra eventuais punições por movimentos pendulares. Os complexos de regimes abrem espaço para oforum-shopping, uma estratégia de buscar os ganhos ao escolher instituições que trazem mais ganhos no momento.

O forum-shopping pode se transformar ora em bandwagoning, ora em soft-balancing. A política externa brasileira historicamente se caracteriza por movimentos em ambas as direções. No entanto, esses movimentos eram, geralmente, caracterizados por governos. Isto é, determinada administração desenhava uma política externa que seria definida ou por uma aproximação maior com os EUA, como foram os casos de Dutra, Castelo e Collor, ou preferiram uma política externa de distanciamento, como foram os casos de Geisel e Lula ${ }^{97}$. A atual configuração global caracterizada pelas alianças rivais e pelos complexos de regimes muda essa estruturação estratégica da política externa brasileira. É possível realizar movimentos pendulares dentro da mesma administração. A opção pelo pêndulo aumentaria a dinâmica desses eixos estratégicos e permitiria um único governo ser, simultaneamente, alinhado e equilibrado.

97 LIMA 1994 e 2005, CEPALUNI e VIGEVANI 2007 
A ideia de pêndulo na política externa brasileira sempre esteve ligada a dois polos antagonistas dentro de um ambiente conflitivo, sistêmico e de guerra aberta por supremacia. O pêndulo de Getúlio Vargas esteve ligado a uma ideia de finitude. Se, por um lado, o pêndulo indicava uma tentativa de ganhos, por outro significava também uma opção final por um dos $\operatorname{lados}^{98}$. Já no contexto da Guerra Fria alinhamento ou equilíbrio eram estratégias possíveis, embora o alinhamento sempre tenha sido basilar. As situações de soft-balancing sempre foram estratégias que procuravam abrir espaços e aumentar as opções frente ao domínio dos EUA na região99.

Agora o cenário é outro. Nada indica que ocorrerá um conflito aberto nos mesmos moldes da Segunda Guerra Mundial. Além disso, o ambiente institucional é muito mais funcional e presente hoje do que nas décadas de 30 e 40 e na Guerra Fria. O fato de que as alianças rivais operam cotidianamente dentro de complexos de regimes é positivo para o Brasil porque eles controlam os desequilíbrios de poder típicos dos anos 30 ou o excesso de concentração de poder da Guerra Fria. O forum-shopping seria, portanto, a forma contemporânea de se exercer um pêndulo.

Existem duas razões adicionais que permitem ao Brasil desenhar uma estratégia pendular. Primeiro, o Brasil é um dos poucos países que pode acessar a OCDE e os BRICS sem fortes antagonismos internos. O Brasil não possui problemas geopolíticos com EUA e China. Os países centrais de ambas as alianças percebem o Brasil como um membro confiável. Segundo, o Brasil não sofre contestações regionais fortes o suficiente para fragilizar drasticamente seu posicionamento internacional. Assim, o Brasil é um país pivotal em um campo material e identitário em disputa com espaço central e importante para ambos os polos. O Brasil talvez seja o único ator pivotal relevante entre OCDE e BRICS.

\footnotetext{
98 MOURA, Gérson - Relações Exteriores do Brasil 1939-1950: mudanças na natureza das relações Brasil-Estados Unidos durante e após a Segunda Guerra Mundial; HILTON, Stanley - Brazil and the Great Powers, 1930-1939 - The Politics of Trade Rivalry.

${ }^{99}$ LIMA - "Ejes Analiticos y Conflicto de Paradigmas en la Politica Exterior Brasilena".
} 
Não há dúvidas que há desacordos domésticos em torno de quais as melhores estratégias de reforma da ordem global. Enquanto administrações petistas buscaram um reformismo mais ativo e contra-hegemônico utilizando alianças com países reformistas, as administrações de direita preferiram estratégias mais brandas e mais próximas de países ocidentais buscando alianças com países do status quo. No entanto, não é possível vislumbrar nenhuma administração abandonando as alianças OCDE e BRICS. A diferença se dará mais no timing, ênfase e sequências das ações táticas e menos de conteúdo sobre o reformismo. Assim, desde que o Brasil se mantenha membro parcial ou total de cada uma das alianças, poderá agir como um pêndulo protegido pelos complexos de regimes. A existência de duas alianças rivais é positiva para o Brasil.

\section{Conclusões}

Neste ensaio identificamos três movimentos internacionais que têm efeito direto sobre as decisões dos diplomatas brasileiros. Primeiro, a reconstrução da ordem global em torno de duas alianças rivais. Segundo, essas alianças disputam e são disputadas. As alianças são fator decisivo na ascensão e queda das grandes potências. Terceiro, há uma incrível proliferação de instituições internacionais. Essa proliferação criou diversos complexos de regimes. Por sua vez, esses complexos abrem espaço para uma estratégia dominante entre os países: o forum-shopping. Os países escolhem em qual instituição irão atuar em determinado momento tendo em vistas as chances de sucesso e de consecução de seus objetivos.

Alianças rivais e forum-shopping permitem ao Brasil exercer ações simultâneas de bandwagoning e soft-balancing, algo impensável em ordens globais anteriores. Isso só é possível porque o Brasil é visto como um parceiro confiável pelos membros de ambas as alianças, mas notadamente EUA e China. O Brasil não tem problemas geopolíticos que incomodem os principais polos de poder global. Assim, se abre o espaço 
para o Brasil reeditar a estratégia pendular de Getúlio Vargas. O Brasil poderá, novamente, jogar uma aliança contra a outra na busca de ganhos políticos concretos. Talvez a tão almejada cadeira permanente no Conselho de Segurança da ONU só seja possível ao Brasil se o pêndulo agir.

\section{Referências Bibliográficas}

ABDENUR, Adriana; ESTEVES, Paulo, e GAMA, Carlos - "BRICS and Global Governance: a two-pronged approach". In Papers of the Fifth BRICS Academic Forum Partnership for Development, Integration \& Industrials. Pretoria: DIRCO, 2014, pp. 52-59.

ACHARYA, Amitav - The End of American World Order. Cambridge: Polity, 2014.

ALTER, Karen e MEUNIER, Sophie - "The Politics of International Regimes Complexity". In Perspective on Politics, Vol. 07 No. 1, 2009, pp. 13-24.

BOND, Patrick -"BRICS and the sub-imperial location". In BRICS: An Anti-Capitalist Critique. Londres: Pluto Press, 2015.

BUSCH, Marc L. - "Overlapping Institutions, Forum Shopping, and Dispute Settlement in International Trade". In International Organization, Vol. 61, No. 4, 2007, pp. 735-61.

CEPALUNI, Gabriel e VIGEVANI, Tullo - "Lula's Foreign Policy and the Quest for Autonomy through Diversification". In Third World Quarterly, Vol. 28, 2007, pp. 1309-1326.

CHIUS, Daniel Y - "International Alliances in the Power Cycle Theory of State Behaviour". In International Political Science Review, Vol. 24, No. 01, 2003, pp. 123-136.

COOPER, Andrew e FAROOQ, Asif - "BRICS and the Privileging of Informality in Global Governance”. In Global Policy, Vol. 04, No. 04, 2013, pp. 428-433.

DAVIS, Christina - More than Just a Rich Country Club: Membership Conditionality and Institutional Reform in the OECD. 2016. Disponivel em https:// www.princeton.edu/ cldavis/files/Davis_OECDmembership_2016.pdf.

HAFNER-BURTON, Emilie - "The Power Politics of Regime Complexity: Human Rights Trade Conditionality in Europe". In Perspectives on Politics. Vol. 07, No. 01, 2009, pp. 33-37.

HAMPSON, Fen e HEIMBECKER, Paul - "The 'new' multilateralism of the twenty-first century". In Global Governance. Vol. 17, No. 03, 2011, pp. 299-310.

HILTON, Stanley - Brazil and the Great Powers, 1930-1939 - The Politics of Trade Rivalry. Austin: University of Texas Press, 1975. 
IKENBERRY, G. John - Liberal Leviathan: The Origins, Crisis, and Transformation of the American World Order. Princeton: Princeton University Press, 2011.

JOHNSON, Tana e URPELAINEN, Johannes - "International Bureaucrats and the Formation of Intergovernmental Organizations: Institutional Design Discretion Sweetens the Pot". In International Organization, Vol. 68, No. 1, 2014, pp. 177-209.

KEOHANE, Robert O. e VICTOR, David - "The Regime Complex for Climate Change”. In Perspectives on Politics. Vol. 09, No. 01, 2011, pp. 07-23.

KIM, Woosang - "Alliance Transitions and Great Power War". In American Journal of Political Science. Vol. 35, No. 04, 1991, pp. 833-850.

KUPCHAN, Charles - "Introduction: Explaining Peaceful Power Transition". In Power in Transition: The Peaceful Change of International Order. Tóquio: United Nations University Press, 2001.

LIMA, Maria Regina Soares - "Ejes Analiticos Y Conflicto de Paradigmas En La Politica Exterior Brasilena”.In America Latina Internacional. Vol. 01, No. 02, 1994, pp. 27-46.

LIMA, Maria Regina Soares - "Aspiração Internacional e Política Externa". In Revista Brasileira de Comércio Exterior. Vol. 82, 2005, pp. 04-19.

NARLIKAR, Amrita - International Trade and Developing Countries Bargaining coalitions in the GATT \& WTO. Nova Iorque: Routledge, 2003.

MEARSHEIMER, John - The Tragedy of Great Power Politics. Nova Iorque: W.W. Norton and Company, 2001.

MONTEIRO, Nuno - Theory of Unipolar Politics. Cambridge: Cambridge University Press, 2014.

MOURA, Gérson - Relações Exteriores do Brasil 1939-1950: mudanças na natureza das relações Brasil-Estados Unidos durante e após a Segunda Guerra Mundial. Brasília: FUNAG, 2012.

ORSINI, Amandine; MORIN, Jean-Frédéric e YOUNG, Oran - "Regime Complexes: a buzz, a boom or a boost for Global Governance?". In Global Governance, Vol. 19, No. 01, 2013, pp. 27-39.

PAUL, T. V. - "Soft Balancing in the Age of U.S. Primacy". In International Security, Vol. 30, No. 01, 2005, pp. 46-71.

PAUL, T. V.- "The accommodation of rising powers in world politics". In Accommodating Rising Powers Past, Present, and Future. Cambridge: Cambridge University Press, 2016.

RAUSTIALA, Kal e VICTOR, David - "The Regime Complex for Plant Genetic Resources". In International Organization, Vol. 58, No. 2, 2004, pp. 277-309. SCHAEFER, Mark e POFFENBARGER, John G. - The Formation of the BRICS and Its Implication for the United States: Emerging Together. Nova Iorque: Palgrave Macmillan, 2014. 
SCHWELLER, Randall - "Bandwagoning for Profit Bringing the Revisionist State Back In”. In International Security, Vol. 19, No. 01, 1994, pp. 72-107.

STUENKEL, Oliver - "Emerging powers and status: the case of the first BRICs summit". In Asian Perspective, Vol. 38, No. 01, 2014, pp. 89-109.

STUENKEL, Oliver - The BRICS and the Future of Global Order. Nova Iorque: Lexington Books, 2015.

WALT, Stephen - The Origins of Alliances. Ithaca, Nova Iorque: Cornell University Press, 1987.

WALT, Stephen - "Why alliances endure or collapse". In Survival, Vol. 39, No. 01, 1997, pp. 156-179.

WALT, Stephen - "Alliances in a Unipolar World". In World Politics, Vol. 61, No. 1, 2009, pp. 86-120.

WALTZ, Kenneth - Theory of International Politics. Long Drove: Wavelong Press, 1979.

WALTZ, Kenneth - "Structural Realism after the Cold War". In America Unrivaled: The Future of the Balance of Power. Ithaca, Nova Iorque: Cornell University Press, 2002.

WENDT, Alexander - "Identity Formation and the International State". In American Political Science Review, Vol. 88, No. 02, 1994, pp. 384-396.

WOHLFORTH, William - "U.S. Strategy in a Unipolar World". In America Unrivaled: The Future of the Balance of Power. Ithaca, Nova Iorque: Cornell University Press, 2002.

WOHLFORTH, William - "Revisiting Balance of Power Theory in Central Eurasia”. In Balance of Power: Theory and Practice in the 21st Century. Stanford: Stanford University Press, 2004. 